\title{
Articles
}

\section{Teacher Self-Efficacy and Instructional Speech: How Teachers Behave Efficaciously in the EFL Classroom}

\author{
Akihiro Omote \\ Birkbeck, University of London
}

In this paper, I explore teachers' self-efficacy and their instructional speech (in Japanese and English) in EFL classrooms in Japan. Mixed methods provided the framework for a questionnaire to 108 teachers followed by interviews with 6 teachers. The survey revealed a common perception that Japanese instructional speech is overused and a perceived conflict between the use of English and Japanese speech, but the interviews found that self-efficacy played a central role in a complex sociocognitive process to optimize efficacy due to distinct qualities of English and Japanese speech. Teacher self-efficacy (TSE) had two functions: an embarrassment buffer and a motivation keeper. Although both functions were conditional in English, they were cognitive and compensatory in Japanese. Along with the converging impact of English and Japanese on TSE, this discrepancy seems to lead to the overuse of Japanese in the process of efficacy optimization. Implications are provided for future instructional speech with an attempt to alleviate the conflict between the use of English and Japanese.

本研究は、教師の自己効力感（Teacher self-efficacy, TSE）を日本の英語教育における instructional speech（授業言語、授業での日本語使用と英語使用）との関係から探ることを 目的としている。研究は、質問紙（108名の日本人教師対象）と、その後行われた6名の教 師へのインタビューを統合する混合法（mixed methods）で行われた。前者では英語と比較 した日本語の過大使用、及び日英両言語の使用上の対立を、また後者では複雑で社会認知 的な授業の最適化プロセスにおいてTSEが中心的役割を担っていることが判明した。TSE には問題回避と動機維持の $2 つ の$ 機能が見られる。しかし、英語は条件限定的、日本語は

JALT Journal, Vol. 39, No. 2, November 2017 
認知的または補償的にこれらの機能に関連しており、双方の関係性ははっきりと異なっ ていた。日本語の過大使用は、この日英言語のTSEへのそれぞれの対立的影響を元に生じ ていると考えられる。この対立を緩和するための授業言語のより良いあり方について考察 し、いくつか提案を試みる。

A growing number of studies have discussed language teachers' self-efficacy (Chacón, 2005; Faez \& Valeo, 2012; Ghonsooly \& Ghanizadeh, 2013; Mak, 2011). Teacher efficacy refers to the extent to which teachers believe they can affect students' learning (Gibson \& Dembo, 1984; Tschannen-Moran \& Hoy, 2001). Although teachers' speech plays a major role in the success of students' language learning, teachers often face a dilemma when choosing between L1 use and target language (TL) use (Brooks-Lewis, 2009; Cook, 2001; Edstrom, 2006; Omote, 2012; Turnbull, 2001). Based on Bandura's social cognitive theory $(1977,1997)$, the aim of this paper is to identify the connection between the choice of the language of instructional speech (Japanese or English) and the source of teacher self-efficacy in an EFL classroom in Japan. I then suggest how teachers can alleviate the conflict between English (the TL) and Japanese (the L1) speech based on a sociocognitive perspective.

In an EFL setting such as Japan where there is no linguistic heterogeneity, the language chosen for instructional speech can be problematic due to the local linguistic environment in a classroom: A majority of learners and teachers share an L1. The situation is distinct from ESL classrooms where a common use of the L2 is indispensable for speakers of different L1s (Atkinson, 1993; Edstrom, 2006). Moreover, a theoretical basis for choosing the language of instructional speech remains elusive. No clear validation or agreement on whether L1 use enhances or hinders TL improvement has been presented (Auerbach, 1993; Macaro, 2005; Turnbull \& Dailey-0'Cain, 2009). However, researchers have generally agreed that there is evidence of social, cognitive, and motivational roles for L1 use that affect learning and are, therefore, espoused by learners and teachers (Alegría de la Colina \& del Pilar García Mayo, 2009; Antón \& DiCamilla, 1999; Brooks-Lewis, 2009).

Despite the recent reforms by the Japanese Ministry of Education, Culture, Sports, Science and Technology (MEXT) stipulating that upper secondary (senior high) school English classes should be taught in English (MEXT, 2011) and the subsequent intensification of lower secondary (junior high) school English classes (as suggested in the English Education Reform Plan Corresponding to Globalization; MEXT, 2014), researchers have argued against the feasibility of so-called "English-only" classrooms at the local level (Glasgow \& Paller, 2016; Kikuchi \& Browne, 2009). A national survey of 
self-reported instructional speech in Japan, for example, found a high ratio of self-reported L1 instructional speech: $47.6 \%$ of 9,726 upper secondaryschool teachers reported that they used more Japanese than English in oral communication classes and $85.2 \%$ of 12,242 upper secondary-school teachers reported they did so in reading comprehension classes (MEXT, 2010).

As teachers' TL use in instructional speech plays a significant role in their self-efficacy (Chacón, 2005; Nishino, 2012), the high ratio of L1 choice by the teachers strongly suggests that teacher self-efficacy (TSE) in practice might fluctuate during instruction. Cook (2001) concluded that we should grant license to teachers to use the L1, although it is still considered problematic by many researchers. Auerbach (1993) pointed out more than 20 years ago that an English-only policy in instruction "rests on unexamined assumptions, and serves to reinforce inequities" (p. 9). However, little is known today about the link between TSE and instructional speech. Therefore, merely standardising classroom communication to "English only" is not necessarily appropriate in a local classroom environment.

\section{Teacher Self-Efficacy and Instructional Speech}

I began from the assumption that TSE and instructional speech may forge a closer link as learners become more successful in classroom tasks. The language teacher functions as a verbal and social aid for supporting learners' mastery of the TL, and teachers make choices of instructional speech based on their experience (Richards \& Lockhart, 1996). However, a connection between TSE and instructional speech has not been explored adequately in terms of the beliefs of teachers (as agents) about efficacy and their instructional speech (behaviour). That is, the question of how the language of instruction can be linked to teacher efficacy is yet to be addressed.

Bandura $(1977,1997)$ posited self-efficacy as agentic beliefs that trigger new actions to conduct a particular task. An agentic belief is a belief of a classroom teacher who might be aware of the TSE that affects his or her practice. Self-efficacy, defined as "beliefs in one's capabilities to organize and execute the courses of action required to produce given attainments" (Bandura, 1997, p. 3), assumes a key role when a teacher reflects on his or her teaching and incorporates the reflection into ongoing regulatory practice that has an accumulating effect over time. Richards and Lockhart (1996) mentioned the importance of reflections on principles that are incorporated into practice. Given this, looking at a teacher's choice of English or Japanese would be a good way to investigate TSE and its relationship with practices that underlie instructional speech. 
Therefore, it is crucial to seek the sources of TSE to predict the mastery or avoidance effects of instructional speech and the degree to which teachers' sense of efficacy plays an active role (Tschannen-Moran \& Hoy, 2001). Morris and Usher (2011), for example, interviewed university teachers about the sources of teacher efficacy, adopting Bandura's (1977) four sources as criteria: (a) mastery experiences (achievement fulfilled by learner and teacher), (b) vicarious experiences (indirect experience through observed achievement), (c) social persuasions (verbal and nonverbal evaluations by others), and (d) physiological and affective states. Their results suggested that TSE relates to sociocognitive aspects more than to mastery; that is, it relates to social persuasion such as students' evaluations, followed by mastery experience-such as students' achievements-and then vicarious experience (e.g., the teacher's own former teachers). The results also implied that teachers' negative experiences were not necessarily likely to lower their sense of efficacy because successful and proficient teachers attributed failures not to internal factors, such as their own incapability, but to external ones, such as a lack of rapport with students leading to a suboptimal classroom atmosphere.

Chacón (2005) explored self-reported TSE of Venezuelan middle school teachers through a survey administered to 100 teachers. The survey revealed that grammar-based strategies, including translation into the L1, correlated positively with self-efficacy, showing a significantly higher mean than communicative strategies did. The data also showed positive correlations between teachers' efficacy and language proficiency, but did not show any correlation between classroom management and proficiency. According to the results, teacher efficacy fluctuated due to proficiency, but the role of instructional speech was unclear because teachers did not specifically mention it. The grammar-translation strategies had a positive effect on TSE, but the classroom-management strategies did not. Interestingly, Edstrom (2006) presented quite similar positive and negative learner feedback regarding teacher L1 use: The learners gave feedback about a teacher's L1 use in the classroom in terms of the teacher's (perceived) motivation.

Therefore, the aim of this paper is to identify the connection between instructional speech and the sources of TSE and to suggest how teachers can use Japanese, English, or both to maximise their self-efficacy. The hypothesis is that TSE positively associates with teachers' use of L1 Japanese. The research questions are

RQ1. Can teachers choose efficaciously when to use English and Japanese in the classroom? 
RQ2. Is teachers' choice of the L1 or the TL for instructional speech associated with self-efficacy?

\section{Method}

\section{A Mixed Methods Design}

An explanatory sequential mixed methods design (Figure 1) with a participant selection model, based on the work of Creswell (2012), provided a common framework for two different phases: quantitative data analysis of survey questionnaire (Study 1), followed by a qualitative data analysis of data from interviews with participants selected based on the outcome of the first study (Study 2). The rationale for the methodology was that, because the survey results would provide only a general picture of the research question, interviews would provide more specific and contextual analysis and elaboration leading to deeper interpretation. Study 2 was a significant part of the framework in that it explored an in-depth, as well as complementary, dimension of the entire study.

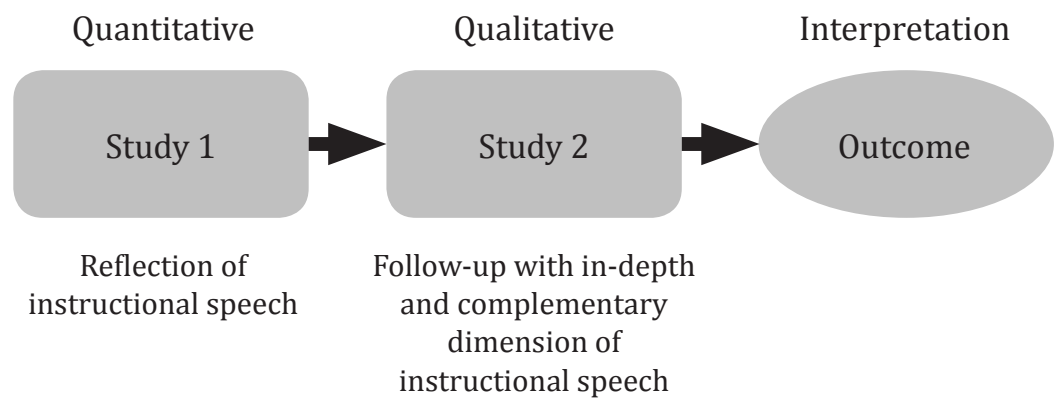

Figure 1. An explanatory sequential mixed methods design. Modified from Creswell (2012, p. 541).

\section{Study 1}

The author recruited participants for Study 1 by sending a questionnaire (see Appendix A) to 175 native Japanese teachers of English and collecting responses from 108 (46 males and 62 females) who taught solo English classes in lower and upper public and private secondary schools in the Shikoku, Kansai, and Kanto areas of Japan. All signed a consent form (a few consented anonymously). Their ages ranged from 20 to 60 years old and 
their years of teaching experience ranged from 1 to 26 years. The answers to items in the questionnaire that were related to their classroom contexts showed that there was no significant association between schools and categories such as linguistic homogeneity, goal, class size, students' achievement, and teaching style.

Polio and Duff (1994) used a qualitative analysis for eliciting categories from the functions of instructional speech. In the current survey, five questions (Items 13-17) were asked about the reflected ratio of instructional speech (Japanese to English) by a proportion (e.g., 4:6). The questions about instructional speech used categories adapted from Polio and Duff: teacher speech in tasks (Item 13), teacher speech in management (Item 14), learner speech in tasks (Item 15), learner speech in management (Item 16), and overall teacher to learner speech ratio (Item 17). A total of 14 six-point Likert-scale items were devised ( 1 = I do not agree at all; 6 = I agree very much) to measure the teachers' self-efficacy as it related to their choice of language for instruction (e.g., "I feel that Japanese/English in my class is efficacious because it is helpful to enhance understanding" [Items 22/29]). The items were created based on five major reasons and purposes that teachers have reported in previous studies: goal-how efficacious the instructional speech is for students' goal achievement (Items 18-20, 25-27); understandinghow efficacious the instructional speech is for students' understanding of the content of the class (Items 21 \& 28); enhancement-how efficacious the instructional speech is for the enhancement of understanding of language features such as grammar (Items 22 \& 29); smoothness-how efficacious the instructional speech is to make the learning activities go more smoothly, for example, in directions (Items 23 \& 30); and enrichment-how efficacious the instructional speech is to enrich learning, for example, to encourage active participation in the class (Items $24 \& 31$ ). These items were adapted from De la Campa and Nassaji (2009); Liu, Ahn, Baek, and Han (2004); and Polio and Duff (1994), who determined speech (L1) functions in EFL instruction.

A principal component analysis (PCA) was conducted with oblique rotation (promax) on the efficacy items. The Kaiser-Meyer-Olkin measure verified the sampling adequacy for the analysis, $\mathrm{KMO}=.79$. All figures for individual 14 items were $>.70$. Bartlett's test of sphericity, $\chi^{2}(91)=1239.09$, $p<.001$, indicated that correlations between items were sufficiently large for the PCA. Cronbach's alpha was .84, which means the reliability of these items was robust. 


\section{Study 2}

Drawing from the initial questionnaire respondents, the author recruited 11 teachers by email to participate in follow-up interviews. These teachers, aged 20 to 50 , had between 1 and 23 years of teaching experience. Teachers asked to participate in this study were those whose ratio of Japanese to English in instructional use was 6:4 or higher based on the results of Study 1 (i.e., dominant L1 use, see below). Six teachers agreed to participate. Table 1 shows demographic details, including pseudonyms. The average reflected ratio of Japanese to English was 7:3. Preliminary interviews by email or telephone revealed that all the teachers spoke Japanese as a native language, taught solo comprehensive English classes to Japanese students, and identified no problematic teacher-student relationships. Most importantly, each represented different teacher characteristics (age, sex, grades taught, experience, etc.). Five of the six teachers had certified high-level English proficiency based on standardized tests.

Mie and Sakura were teachers at different lower secondary schools. Mie was younger, with only 3 years of teaching experience. Her TOEIC (Test of English for International Communication) score was 880. Her Japanese to English reflection was 6:4. Sakura had 20 years of experience teaching in Japan. Her Japanese to English reflection was 9:1; she was not confident about using English; and she believed it was not possible to use more English because the students lacked the skills and experience to gain confidence in English.

Kei had 9 years of teaching experience with a variety of overseas experiences. Her TOEIC score was 935. Despite her preference to conduct classes using English, she felt that teaching grammar in English was pointless, considering the college entrance examinations. She believed that success in the examinations required the students to have more understanding of the TL in their L1 than would be possible by using the TL as is required by school policy. Kei's Japanese to English reflection was 8:2.

Ichiro was in his late 40s; he had 7 years of prior teaching experience in California and had been teaching at his current school for 14 years since then. Ichiro used Japanese to explain grammar because his goal was to prepare his students for their university entrance examinations. His reflection was 7:3.

Katz studied for a year in the United States before becoming a teacher. His IELTS (International English Language Test System) score was 7.0. His reflection ratio was 7:3. He was not completely convinced about the Englishonly policy declared by MEXT. He had once tried an English-only class, which 
was not successful because he was not able to ensure good communication with his students.

Taro was the oldest with 10 years of teaching experience. Despite having a high English proficiency test score (TOEIC 985), Taro's reflection was 6:4.

Table 1. Study 2: Participants' Backgrounds

\begin{tabular}{|c|c|c|c|c|c|c|c|c|c|}
\hline  & $\stackrel{\infty}{\infty}$ & $\stackrel{凶}{\mathscr{D}}$ & 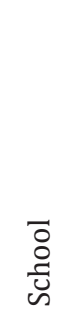 & 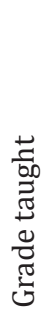 & 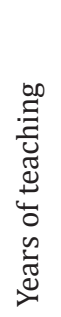 & 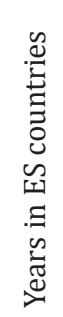 & 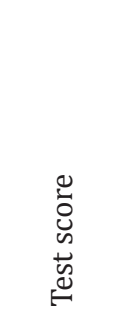 & 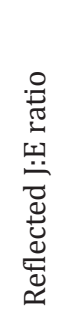 & 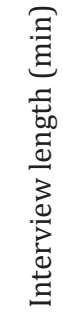 \\
\hline Mie & $\begin{array}{l}\text { late } \\
20 \mathrm{~s}\end{array}$ & $\mathrm{~F}$ & LS & 1 & 3 & $<2$ & $880(\mathrm{~T})$ & $6: 4$ & 79 \\
\hline Katz & $\begin{array}{l}\text { late } \\
20 s\end{array}$ & M & US & 5 & 4 & 1 & $\begin{array}{c}870(\mathrm{~T}) \\
7.0(\mathrm{I})\end{array}$ & $7: 3$ & 74 \\
\hline Kei & $\begin{array}{l}\text { late } \\
30 \mathrm{~s}\end{array}$ & $\mathrm{~F}$ & US & 4 & 10 & $<2$ & $935(\mathrm{~T})$ & $8: 2$ & 106 \\
\hline Sakura & $\begin{array}{c}\text { early } \\
40 \mathrm{~s}\end{array}$ & $\mathrm{~F}$ & LS & 3 & 20 & $<2$ & 2nd (S) & $9: 1$ & 75 \\
\hline Ichiro & $\begin{array}{l}\text { late } \\
40 \mathrm{~s}\end{array}$ & M & US & 6 & 23 & 7 & 1st (S) & $7: 3$ & 66 \\
\hline Taro & $\begin{array}{c}\text { early } \\
50 \mathrm{~s}\end{array}$ & M & UNV & 7 & 10 & $<2$ & $985(\mathrm{~T})$ & $6: 4$ & 55 \\
\hline
\end{tabular}

Note. LS = lower secondary (junior high) school; US = upper secondary (senior high) school; UNV = university; ES = English-speaking; T = TOEIC (Test of English for International Communication); I = IELTS (International English Language Test System); S $=$ STEP (Standardized Test for English Proficiency); J/E = Japanese to English; grade taught = 1 (1st-year secondary) to 7 (1st year tertiary).

The author conducted six semistructured interview sessions ranging from 55 to 106 minutes in a closed and quiet meeting environment. The interviews were recorded using a digital recorder after confidentiality of personal information was assured and the interviewees had signed formal consent forms. The data were transcribed verbatim. After the initial coding of transcripts, the author invited the participants for follow-up interviews, 
either in person or by email, to confirm and modify the transcription. All teacher comments were translated by the author.

The main goal of the interviews was to elicit how TSE had developed and changed over time in terms of Bandura's (1977) four sources of self-efficacy adapted as coding criteria by Morris and Usher (2011). To this end, the author developed an interview protocol (se Appendix B) by modifying that of Morris and Usher's study.

The transcripts were coded using ATLAS ti.7 (Friese \& Ringmayr, 2015) through two steps. For the first step, 33 quotations from six participants were coded into four efficacy-source categories-mastery experiences (ME), vicarious experiences (VE), social persuasions (SP), physiological and affective states (PA) - and five linguistic codes-Japanese (JP), nonchoice of English (non-EN), English (EN), nonchoice of Japanese (non-JP), and nonlanguage (NL). This primary coding allowed for the two strands of efficacy and language to be coded simultaneously. For example, the author coded the comment "English is a tool to encourage myself to create the physiological rhythm inside of me" as PA as well as EN.

Next, the quotations coded as NL were eliminated because the purpose was to see the link between self-efficacy and language choice. The secondary coding was then carried out using an open coding approach in an attempt to explore linguistic functions in each coded paragraph. This was to identify and classify functional types in each source group (ME, VE, SP, or PA); functions of self-efficacy that were common across each type of speech (EN, JP, non-EN, non-JP) emerged in this process (see Table 2).

\section{Table 2. Types of Self-Efficacy Sources and Functions of Each Coding}

\begin{tabular}{|c|c|c|c|}
\hline Source & Code & Types & Functions \\
\hline \multirow[t]{2}{*}{ ME } & EN & $\begin{array}{l}\text { 1. Perceived former success in class (e.g., } \\
\text { "The most fruitful class I ever had was one I } \\
\text { taught from my } 4 \text { th year for three consecu- } \\
\text { tive years. I taught them from first to third } \\
\text { grade." [Kei]) }\end{array}$ & $\begin{array}{l}\text { Conditionally } \\
\text { motivational }\end{array}$ \\
\hline & $\mathrm{JP}$ & $\begin{array}{l}\text { 2. Mastery of cognitive strategies (e.g., "They } \\
\text { prefer to be convinced by the reliable L1 } \\
\text { rather than to be made confused by the } \\
\text { ambiguous English. They like to learn things } \\
\text { through logical explanation." [Ichiro]) }\end{array}$ & Cognitive tool \\
\hline
\end{tabular}




\begin{tabular}{|c|c|c|c|}
\hline Source & Code & Types & Functions \\
\hline VE & EN & $\begin{array}{l}\text { 3. Learning pedagogical skills by observing } \\
\text { models (e.g., "I am working with native as- } \\
\text { sistants, so I was convinced and encouraged } \\
\text { to use the expressions they used. I mean I } \\
\text { owe something to them." [Mie]) }\end{array}$ & $\begin{array}{l}\text { Motivational as } \\
\text { a model }\end{array}$ \\
\hline \multirow[t]{3}{*}{ SP } & EN & $\begin{array}{l}\text { 4. Students' informal comments and } \\
\text { evaluations (e.g., "The room always af- } \\
\text { forded opportunities for the small number } \\
\text { of students to share a virtual English life. In } \\
\text { such a specialized condition, they were ready } \\
\text {..." [Sakura]) }\end{array}$ & $\begin{array}{l}\text { Conditionally } \\
\text { motivational }\end{array}$ \\
\hline & $\mathrm{JP}$ & $\begin{array}{l}\text { Same as } 4 \text { (e.g., "[I was] usually acting as an } \\
\text { easy teacher using the L1. Then students } \\
\text { would respond to me, being relaxed and } \\
\text { open-minded to me, and my class." [Taro]) }\end{array}$ & $\begin{array}{l}\text { Compensatory } \\
\text { behaviour }\end{array}$ \\
\hline & $\begin{array}{l}\text { Non- } \\
\text { EN }\end{array}$ & $\begin{array}{l}\text { 5. Negative social responses (e.g., "I tried, } \\
\text { for the discipline of the students but in vain, } \\
\text { to make myself understood in English. Then } \\
\text { I decided to use Japanese to do so. My goal } \\
\text { was to manage my class, anyway." [Mie]) }\end{array}$ & $\begin{array}{l}\text { Embarrassment } \\
\text { avoidance }\end{array}$ \\
\hline \multirow[t]{3}{*}{ PA } & EN & $\begin{array}{l}\text { 6. Positive physiological and affective states } \\
\text { (e.g., "We can make an English-only class } \\
\text { with humour and laughter. Yes, I know it... } \\
\text { Laughter was a key factor then." [Sakura]) }\end{array}$ & $\begin{array}{l}\text { Conditionally } \\
\text { motivational }\end{array}$ \\
\hline & $\mathrm{JP}$ & $\begin{array}{l}\text { Same as } 6 \text { (e.g., "I use grammatical jargon, } \\
\text { maru sankaku shikaku [circle, triangle, and } \\
\text { square], in a hard-and-fast manner. It feels } \\
\text { strange, but they are invincible and stabiliz- } \\
\text { ing tools of mine." [Katz]) }\end{array}$ & $\begin{array}{l}\text { Compensatory } \\
\text { motivation }\end{array}$ \\
\hline & $\begin{array}{l}\text { Non- } \\
\text { JP }\end{array}$ & $\begin{array}{l}\text { 7. Nervousness (e.g., "When I get annoyed, I } \\
\text { avoid Japanese and use English instead. I am } \\
\text { afraid that I would be insulting. I don't know, } \\
\text { but English alleviates such a feeling inside } \\
\text { me." [Taro]) }\end{array}$ & $\begin{array}{l}\text { Embarrassment } \\
\text { avoidance }\end{array}$ \\
\hline
\end{tabular}

Note. $\mathrm{ME}=$ mastery experiences; $\mathrm{VE}$ = vicarious experiences; $\mathrm{SP}=$ social persuasions; $\mathrm{PA}=$ physiological and affective states; EN = English; JP = Japanese; Non-EN = nonchoice of English; Non-JP = nonchoice of Japanese. 
Efforts to strengthen the validity of the coding were twofold. First, to detect data patterns, the author revisited cross-matrix codes, anomalies in the transcripts, all field notes, summaries, recorded videos, and the original interview recordings. As was the case with Morris and Usher (2011), various strands of these processes substantiated the relationships between sources and self-efficacy as well as confirmed the explicit acknowledgement of the relationships by each participant. Second, if necessary and possible, the author exchanged emails with participants, visited participants at their schools, or did both to either replicate or reconcile some controversial points of the transcripts.

After several coding-training sessions, two raters (including the author) calculated an intercoder reliability based on a random selection of approximately $15 \%$ of the transcriptions. The obtained Kappa statistic from this early assessment was .909 , revealing a very good or high degree of agreement. Disagreements between the raters were resolved prior to the actual coding process through mutual understanding by the raters.

\section{Results}

\section{Results of Study 1}

Table 3 summarises the comparison between two categorical variables: schools and ratio of Japanese to English use in the classroom. Ratios of 6:4 and over were tallied in the high category, 5:5 and under in the low category. Fisher's exact test revealed that there were no significant associations, except teacher's L1 in task, $\chi^{2}(1)=9.48, p=.003, \varphi=.296$. This showed that the odds of upper secondary school teachers' L1 use being over $50 \%$ were 13.57 times higher than those of the lower secondary school teachers. However, the overall outcome was a greater use of L1 regardless of school or agent (i.e., teacher or learner).

Table 4 presents the mean degree of agreement on the efficacious functions of the two languages. Independent-samples $t$ tests with Bonferroni correction compared the means of each paired item (e.g., Items 18 and 25, see Appendix A) and found no significant differences on the three pairs in goal (student's achievement). However, teachers assumed understanding, enhancement, and smoothness as efficacious functions of Japanese significantly more than they did so for English: understanding, $t(214)=11.45, p$ $<.01, d=1.56$; enhancement, $t(214)=10.56, p<.01, d=1.44$; smoothness, $t(214)=7.89, p<.01, d=1.08$. However, teachers agreed on enrichment as an efficacious function, not of Japanese but of English, and this too was significant, $t(214)=-3.10, p<.01, d=0.42$. 
Table 3. Summary of Frequency in L1 (Japanese) Ratios

\begin{tabular}{|c|c|c|c|c|c|c|c|}
\hline \multirow{2}{*}{ L1 (Japanese) use } & \multicolumn{2}{|c|}{ LS $(n=59)$} & \multicolumn{2}{|c|}{ US $(n=49)$} & \multirow{2}{*}{$\chi^{2}$} & \multirow{2}{*}{$p^{\mathrm{a}}$} & \multirow{2}{*}{$\varphi$} \\
\hline & Low & High & Low & High & & & \\
\hline Teacher's L1 (task) & 13 & 46 & 1 & 48 & 9.484 & $.003^{* *}$ & .296 \\
\hline $\begin{array}{l}\text { Teacher's L1 } \\
\text { (management) }\end{array}$ & 3 & 56 & 2 & 47 & .061 & 1.000 & .024 \\
\hline Students' L1 (task) & 17 & 42 & 7 & 42 & 3.269 & .103 & .174 \\
\hline $\begin{array}{l}\text { Students' L1 } \\
\text { (management) }\end{array}$ & 0 & 59 & 2 & 47 & 2.454 & .204 & -.151 \\
\hline $\begin{array}{l}\text { Teacher to student } \\
\text { ratio }\end{array}$ & 14 & 45 & 6 & 43 & 2.340 & .143 & .147 \\
\hline
\end{tabular}

Note. LS = lower secondary school; US = upper secondary school.

${ }^{a}$ Fisher's exact test. ${ }^{* *} \mathrm{p}<.01$. Bonferroni correction was applied.

Table 4. Mean Degree of Agreement on the Efficacious Functions of Japanese and English $(N=108)$

\begin{tabular}{llcccccc}
\hline \multirow{2}{*}{$\begin{array}{l}\text { Item } \\
\text { no. }\end{array}$} & $\begin{array}{l}\text { Efficacious } \\
\text { functions }\end{array}$ & \multicolumn{9}{c}{ Japanese } & \multicolumn{2}{c}{ English } & \multirow{2}{*}{$t$} & \multirow{2}{*}{$d$} \\
\cline { 2 - 6 } 18,25 & Goal & 4.56 & 0.99 & 4.49 & 1.06 & 0.464 & 0.47 \\
& (effectiveness) & & & & & & \\
19,26 & Goal (necessity) & 4.87 & 0.84 & 4.53 & 1.07 & 2.610 & 0.35 \\
20,27 & Goal & 4.69 & 0.88 & 4.52 & 1.05 & 1.331 & 0.18 \\
& (significance) & & & & & & \\
21,28 & Understanding & 5.23 & 0.71 & 3.72 & 1.18 & $11.447^{* *}$ & 1.56 \\
22,29 & Enhancement & 5.10 & 0.79 & 3.67 & 1.17 & $10.559^{* *}$ & 1.44 \\
23,30 & Smoothness & 4.81 & 0.92 & 3.60 & 1.29 & $7.892^{* *}$ & 1.08 \\
24,31 & Enrichment & 4.30 & 1.14 & 4.74 & 0.96 & $-3.102^{* *}$ & 0.42 \\
\hline
\end{tabular}

Note. Chronbach's alpha $=.90$ (Japanese) and .91 (English). Bonferroni correction was applied. Item no. $=$ number of item on questionnaire in Appendix A.

${ }^{* *} p<.01$. 


\section{Results of Study 2}

Table 2 presents a summary of the relationship between the sources of TSE and language revealed in the interview data. Two features, embarrassment avoidance and motivation, emerged as the most common functions across source types. The functions of the four self-efficacy sources (ME, VE, SP, and PA) are presented below.

ME was the most influential source, revealing two types: perceived former success in class (EN) and mastery of cognitive strategies (JP). These source types exemplify different aspects of TSE depending on the language type. English acts as an incentive for students to learn and Japanese enhances students' understanding; both of which serve to increase TSE. For example, because she had a good relationship with students in her previous school, Kei used both English and Japanese and was able to share a bond with students through teaching strategies that motivated students to produce output. In other words, Kei believed that her deliberate alternation of language of instruction not only facilitated students' mastery of communication in English but also helped increase her self-efficacy. Ichiro, in contrast, renounced the communicative teaching method and instead espoused a target of mastering English by focusing on learners' higher cognitive abilities such as logical thinking and inferential strategies. Ichiro's efficacy stemmed from emphasising the students' preference for Japanese as a resource and their success studying in Japanese rather than the unfamiliar and artificial English. Ichiro articulated his belief by saying, "They prefer to be convinced by the reliable L1 rather than to be made confused by the unclear foreign language. They like to learn things through logical explanation."

VE was the least powerful source of the four: The coder assigned only English (no Japanese) for learning pedagogical skills by observing models (EN). Mie's awareness of the practices of native English-speaking teachers occasionally motivated her to imitate them to gain efficacy in her classroom. However, she and the other teachers never developed similar strategies to gain efficacy from their instructional speech in Japanese. Thus, VE contributed little to TSE via Japanese.

SP was the second most influential source with the most diverse functions. Three features were predominant: Students' informal comments and evaluations (both EN and JP) and negative social responses (non-EN). Teachers spoke of students' comments and evaluations as a strong source for efficacy building. Some teachers emphasised the importance of the motivational classroom environment, and others emphasised their own compensatory behaviour. One example is Sakura's experience of the motivational 
classroom environment (EN). She believed that the extra measures that she had created for the enhancement of students' learning motivation-room preparation, interior decoration-motivated the students to refrain from using Japanese:

The room always afforded opportunities for the small number of students to share a virtual English life. In this particular condition, they were ready ... it didn't matter if they could speak well .... but they felt like using English within the space from beginning to end! (Sakura)

By using Japanese, Taro obtained similar efficacious control via the students' responses. Despite his highly proficient English, the social persuasion of his students seemed to have affected Taro's natural inclination to use Japanese and made him more aware of his capability:

Many other teachers spoke strictly in English in the school. Nonetheless, I was, at times, a very kind teacher. I knew it .... [I was] usually acting as an easy teacher, using Japanese. Then students would respond to me and my class, being relaxed and open minded. All of us enjoyed the circumstances, you know. (Taro)

The third type of SP was negative social responses (non-EN). SP was notably associated with embarrassment avoidance by nonchoice of English, suggesting that teachers quite a few times felt they had no other choice but to use Japanese because of reservations about English, similar to the results found by Polio \& Duff (1994). This type, therefore, functioned as embarrassment avoidance. Mie described one of her past experiences in which poor discipline made having the class in English too much of a challenge. She explained the situation as follows:

I was at a loss what to do the moment I first became a teacher.. .. My English worked all right, however, sometimes it didn't do any good at all. I tried my best for the discipline of the students to make myself understood in English [for management], but to no avail. Then I decided to use Japanese to do so. My goal was to manage my class, anyway. (Mie)

PA was the third most influential source. Three features emerged: positive physiological and affective states (EN) and (JP) and nervousness (non-JP). 
Sakura represented PA (EN) when she said, "I once successfully motivated my students to make an English-only class with humour and laughter. Yes, I know it ... Laughter was a key factor then."

Katz used a unique vocabulary (JP) when he explained grammar to his learners; it included Japanese terms such as maru sankaku shikaku [circle, triangle, and square] to highlight important grammatical points. He used this particular language in every instance in the classroom. It had become an active source of Katz's self-efficacy because he felt a steady student response that made him feel efficacious. Such a sense of efficacy seemed to have made him a more reliable teacher, and he believed that it would also make his students stronger.

The other type of PA was non-JP. Because this type functioned as an emotional problem-solving feature-that is, avoiding an uncomfortable emotional state (JP) by adopting a stable counterpart (EN) - it was coded nervousness. Taro refrained from using Japanese and instead used English in a moment of anger caused by students' bad and slothful manners. He explained that the students' behaviour fuelled his irritation and that, despite the predominance of Japanese for instruction in his class, he expressed his frustration in English. By using English, he believed he was capable of keeping his cognition virtually unaffected by his emotions, similar to the results in Keysar, Hayakawa, \& An (2012).

In sum, TSE manifested itself as having two functions: embarrassment avoidance and motivational inclination. However, these features in English (the TL) were limited in certain conditions as seen in the case of Kei's sharing bonds, Sakura's special room, and Taro's irritation, while the functions in Japanese (the L1) were cognitive and compensatory, working to alleviate the problems of TL use for foreign language learning (see De la Campa \& Nassaji, 2009; Littlewood \& Yu, 2009).

\section{Discussion}

\section{Study 1}

Study 1 verified that the L1 was the principal language of instruction regardless of school and agent, which suggested a disproportionate use of the L1 in overall instructional speech. Previous quantitative research has presented a similar pattern. For example, Kaneko (1992) observed the utterances in one class of each of 12 EFL secondary school teachers and revealed a 71.8\% use of Japanese by the teachers, with time sampling applied to the protocol data. More recently, Liu, Ahn, Baek, and Han (2004) observed the utterances in 
one class of each of 13 high school EFL teachers in South Korea and showed L1 (Korean) use to be $68 \%$.

Teachers' self-reports in the current study, however, have given us a different overview of this landscape. Although the teachers agreed on the Japanese functions in understanding, enhancement, and smoothness, they presented a rather mixed view on goal with no significant differences between Japanese and English in helping students set goals in terms of effectiveness, necessity, and significance. They conversely acknowledged an efficacious function of English in enrichment; that is, teachers held a view that the TL was a valid means of encouraging students' participation. Thus, these findings reveal teachers' complex self-efficacy pertaining to instructional speech, specifically for goal setting.

The results of Study 1 (understanding, enhancement, smoothness, and goal in Table 4) highlight the fact that teachers' English-related strategic behaviour is complex in two ways: conflicting beliefs about the function of language in goal setting and the occasional compensatory use of L1 when there is a gap in conversation or when students reach a plateau of understanding. Through interviews, Omote (2012) revealed teachers' conflicts about an English-only class, demonstrating a variety of causes of teachers' use of Japanese, such as limited chances to use English in Japanese society, limited cognitive effect, and limited effects in terms of student motivation. Omote pointed out that these limitations might undermine teachers' support for education that has mastery of English as a goal, as they influence teachers' behaviour through their beliefs about their instruction.

Study 1 may also demonstrate a sociocognitive function of L1 (see Burden, 2000; McDowell, 2009). With teachers' misgivings compensated for in part by making use of Japanese in classrooms, their self-evaluation would pay a high price for excluding the L1, which might lead to a lack of understanding, enhancement, and smooth communication. From the perspective of sociocognitive classroom interactions, therefore, miscommunications and conflicts may be connected in some way to teacher self-evaluation and self-efficacy when teachers attempt to use only the TL to communicate (see Chacón, 2005; Mak, 2011).

\section{Study 2}

Figure 2 illustrates the outcomes of Study 2, focusing on two distinctive highlights categorised by the source of TSE (an embarrassment avoidance function) and three-way motivational functions: (a) a motivational function under specific conditions (conditional), (b) a motivational function for 
activating cognition (cognitive), and (c) a motivational function by compensation (compensatory). These three functions can be collectively referred to as CCC-motivational functions. Specifically, we should note the different qualities between English and Japanese features: the conditional function of EN, and the cognitive and compensatory functions of JP. This means that Japanese and English may alternate in teacher talk following TSE-driven functions. TSE is, therefore, associated with a change in instructional speech between English and Japanese. The primary cause of this particular efficacybehaviour connection was the effect of students' engagement for ME and SP, suggesting that TSE may undergo fluctuation with feedback from learners' mastery or response.

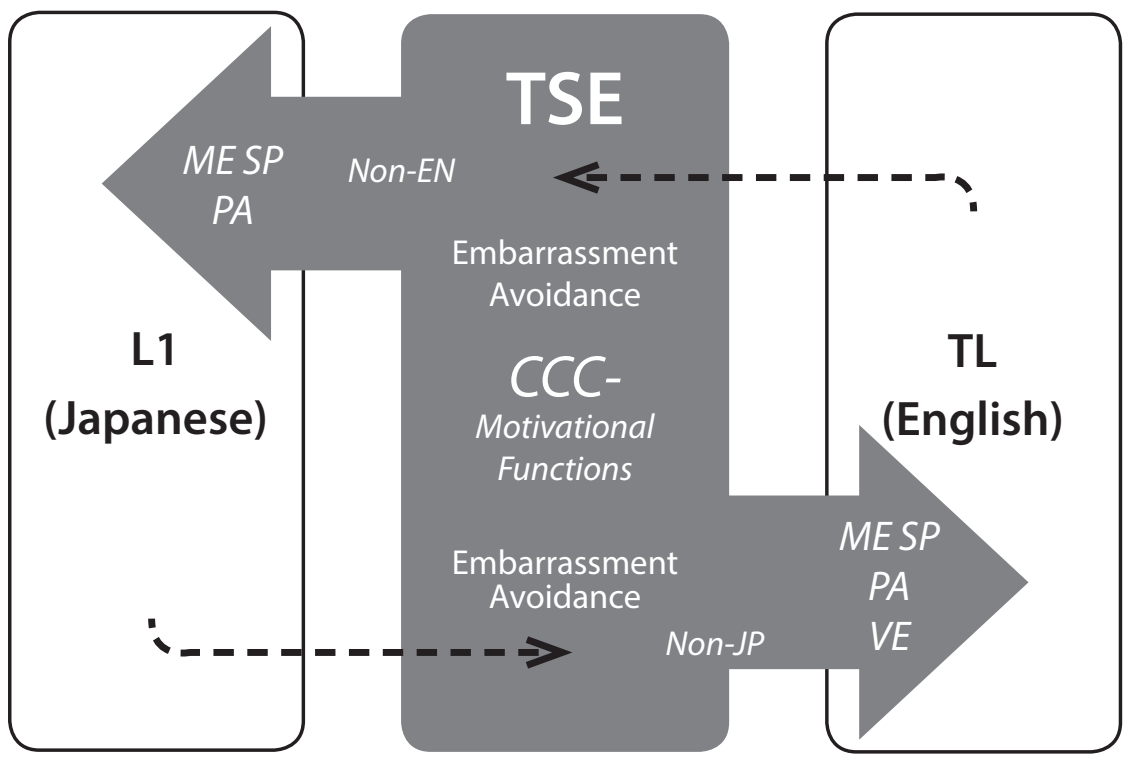

Figure 2. A conceptual scheme of the relationship between teacher self-efficacy (TSE) and language. TSE has two functions related to teachers' speech (embarrassment avoidance and conditional-, cognitive-, and compensatorymotivational functions [CCC-motivational functions]). The two large coloured arrows represent sources of self-efficacy and the direction, and the white squares (Japanese and English) represent behaviour (speech). Dotted arrows show a feedback circulation for teachers' speech optimisation in the classroom environment. $\mathrm{ME}=$ mastery experiences, $\mathrm{VE}=$ vicarious experiences, $\mathrm{SP}=$ social persuasions, $\mathrm{PA}=$ physiological and affective states; Non$\mathrm{EN}=$ nonchoice of English, Non-JP = nonchoice of Japanese. 
From a sociocognitive perspective, Kei's speech alternation indicates that meaningful feedback and interactions accumulated longitudinally among her efficacy, speech, and students' responses. However, this practice did not cause her efficacy to deteriorate, instead optimising it in the face of environmental difficulty (see Morris \& Usher, 2011, and Weiner, 1986, for other successful teacher responses to failure). The important finding is that when supported by Japanese used as compensation or to aid students' understanding, self-efficacy can stabilise within a framework of minimum fluctuation. Support for this interpretation was in Kei's following explanation:

After all, the kind of environment students are learning in, and how you should use it, are extremely important. My experiences taught me the lesson that I could be capable of improving students' English ability, whatever situation I may address. (Kei)

A reciprocal effect manifested itself because Kei chose Japanese not only to exert a motivational function for learners but also to enable herself to contribute to the establishment of an effective classroom environment particularly for students with little or no motivation.

On the other hand, scarcity of cognitive and affective feedback from learners limits the motivational function of teachers' using English. Sakura and Kei's efficacy from PA and ME were evidence of this. Sakura felt efficacious when she got feedback from students indicating their motivation, but this feedback was scarce. Kei shared a quite similar opinion. This led to Sakura making a strategy of carefully preparing questions to elicit such feedback, one example of which was "laughter." In this respect, Sakura's source of efficacy was derived mostly from her actions to motivate students. Sakura discussed the manipulation of laughter as a type of conditioned feedback from motivated learners:

You need tactics to elicit laughter. Without tactics, I get less. The key is to question students so you may get good responses. You cannot get it by routine. Prepare well and then make each question motivational. Hard job, you know, but there is no other way. (Sakura)

The present study adopted mixed methods that minimise validity and reliability deficits and maximise credibility (see Creswell, 2012). However, 
vulnerabilities still potentially exist. Researcher bias seems to be one of the most important because case studies can never be completely objective. Bias may also lie in participants' responses when they talk about sensitive and personal issues, such as how exactly they feel motivated in embarrassing situations (Creswell, 2012; Morris \& Usher, 2011).

Another limitation is that the present study found no vicarious model of Japanese use, which is in disagreement with Morris and Usher's (2011) finding that teachers behave efficaciously through vicarious experience. There might have been a drawback in the way this study elicited vicarious experiences linked with the L1 because the primary focus of interview protocol was the English-only policy. It may be appropriate to say, therefore, that teachers paid no attention to the linkage between L1 and vicarious experience rather than to say there were no such models. In future research I will investigate the source of language teachers' self-efficacy from this point of view.

\section{Conclusion}

The aim of this paper was to identify the connection between instructional speech and the source of TSE and to suggest how teachers can use L1 Japanese and TL English for self-efficacy. First, the mixed methods study demonstrated teachers' unbalanced choice of L1 and partly verified Littlewood and Yu's (2009) hypothesis that the L1 has an influence on the functions of TSE in the cognitive and compensatory dimensions of instructional speech. Teachers' ongoing motivational engagement works for this as a primary role of TSE despite their conflicts between goal setting for and mastery learning of the targeted English (Omote, 2012), together with contingent learner feedback (Macaro, 2005).

Second, teachers' behaviour in the choice of the L1 or TL was mixed. Despite the dominant use of L1, there was distinct agreement among teachers on the effect of English on their self-efficacy in terms of enrichment or students' active participation. Nishino (2012) illustrated how students' conditions influence classroom practices: "Teacher cognition is situated in their own local contexts, and teachers generally think about their students' conditions" (p. 392). Therefore, TSE should be partly influenced by both languages to different degrees depending on which of the students' goals (i.e., entrance examinations, communication, and classwork) the teacher is targeting in foreign language learning (Nishino \& Watanabe, 2008; Turnbull, 2001).

The present study revealed that teachers' speech hinges on a fluctuating sense of TSE. Two powerful functions of the instructional speech emerged 
connected with TSE: (a) an embarrassment buffer, which operated to avoid and alleviate a contingent classroom difficulty (see Moafian \& Ghanizadeh, 2009), and (b) an agentic motivation keeper, which worked more longitudinally across languages to maintain self-efficacy in learning and teaching. However, the function in the speech differed between languages, with the English function being conditional and the Japanese function being cognitive and compensatory, which eventually yielded L1 dominancy in the language of instruction.

The study shed light on the issue of maximising and optimising instructional speech. The results supported the idea that a teacher can optimise instructional language as well as maximise TSE. At the same time, however, the results showed that maximisation of the target of enrichment and goal setting has yet to be adequately attempted. To this end, therefore, we should consider three points.

First, there is a caveat regarding how TSE forms and functions with instructional speech, what Turnbull (2001) called an overreliance on the L1: Dominance of the L1 implies its unnecessary use or overreliance on it. This may be partly attributed to the disagreement and insufficient guidance about how and to what extent teachers should decrease the L1 to boost the use of TL. The present data, in this regard, demonstrate a potential impact of TSE that would enhance the choice of TL in certain particular conditions, as was partially shown in Kei's, Mie's, Sakura's, and Taro's cases. Importantly, however, TSE may influence various dimensions of coursework norms (e.g., classroom management, communication, examinations). This aspect of TSE might help students to understand the TL. However, understanding of the TL does not necessarily lead to a significant goal setting and enrichment (or active participation) in the language classrooms, as the data have shown in the current studies.

Another assumed factor is social. As Katz and Ichiro illustrated, for example, teachers opt to use the L1 themselves to maintain TSE. They used the L1 not due to overreliance but rather for social purposes such as to adapt to students' cognitive and socioeconomic conditions. Alternatively, those teachers' previous learning experiences affected TSE; they regarded their own past experiences of learning grammar for university entrance examinations as a practical purpose for learning English at the secondary school level. Because a large number of junior and high school level teachers with the aim of preparing students for the entrance examination use the L1 to remain efficacious (Nishino, 2012; Nishino \& Watanabe, 2008), this type of teacher belief could form a situational source of self-efficacy and eventually 
a bias towards L1 use. Various modifications of the school situation, including the entrance examination system, might make a difference in teachers' experiences and how this affects their efficacy.

Third, the dynamics of TSE predict a further implication: the possibility for a new kind of teacher training with the goal of optimisation of TSE. Given that efficacy is pivotal in the change from one event into another, the alternative turns from one language to another will greatly depend on the contingent nature of the environment as well as on the students' feedback to the teacher (i.e., Mie's nonchoice of English or Taro's refusal to use Japanese, both of which function as embarrassment avoidance). Morris and Usher (2011) pointed out that an awareness of self-efficacy for self-regulation can allow teachers to behave proactively and confidently during negative events and to dispel misgivings of failure in a task. Therefore, teacher training for this kind of self-regulatory competence-separate from the traditional practice of core linguistic proficiency-is significant and helpful for teachers to maintain self-efficacy with respect to better instructional speech such as, for example, reduction and refinement of L1 use and to enhance the greater use of the TL. More specifically, as both L1 and TL remain inextricably tied in a given context of instructional speech, the ability of the teacher to focus on how best to use the L1 matters most for the enhancement of TL use. Moreover, discussing the ways teachers can qualitatively refine or reduce use of the L1 will virtually open the door to global approaches, such as MEXT's (2014) reforms or the promotion of English as an international language (Marlina, 2013). Therefore, it would give us a further idea of how to turn a foreign language into an additional language in an authentic sense.

The current studies represent a new interpretation for future investigations about the relationship of self-efficacy with instructional speech in Japan. Because of complex classroom circumstances (speaking targeted content through targeted language) and environment (speaking in a limited environment and condition), there is no monolithic way to predict the best dynamics of instructional speech. However, it is not a particular language but a behaviour that motivates classroom agents, conveys meanings, affects teacher and student self-efficacy, and enhances local interactions. In this respect, this study provides the first clue as to how teaching experiences keep teachers efficacious and how they foster effective functions in EFL settings.

Akihiro Omote is currently a student in a MSc program jointly provided by the Birkbeck, University of London, and UCL-IOE (University College London, Institute of Education). 


\section{References}

Alegría de la Colina, A., \& del Pilar García Mayo, M. (2009). Oral interaction in taskbased EFL learning: The use of the L1 as a cognitive tool. International Review of Applied Linguistics in Language Teaching, 47, 325-345. https://doi.org/10.1515/iral.2009.014

Antón, M., \& DiCamilla, F. J. (1999). Socio-cognitive functions of L1 collaborative interaction in the L2 classroom. The Modern Language Journal, 83, 233-247. https://doi.org/10.1111/0026-7902.00018

Atkinson, D. (1993). Teaching monolingual classes. New York, NY: Longman.

Auerbach, E. R. (1993). Reexamining English only in the ESL classroom. TESOL Quarterly, 27, 9-32. https://doi.org/10.2307/3586949

Bandura, A. (1977). Self-efficacy: Toward a unifying theory of behavior change. Psychological Review, 84, 191-215. https://doi.org/10.1037//0033-295x.84.2.191

Bandura, A. (1997). Self-efficacy: The exercise of control. New York, NY: Freeman.

Brooks-Lewis, K. A. (2009). Adult learners' perceptions of the incorporation of their L1 in foreign language teaching and learning. Applied Linguistics, 30, 216-235. https://doi.org/10.1093/applin/amn051

Burden, P. (2000). The use of the students' mother tongue in monolingual English "conversation" classes at Japanese universities. The Language Teacher, 24(6). Retrieved from http://jalt-publications.org/tlt/archive

Chacón, C. T. (2005). Teachers' perceived efficacy among English as a foreign language teachers in middle schools in Venezuela. Teaching and Teacher Education, 21, 257-272. https://doi.org/10.1016/j.tate.2005.01.001

Cook, V. (2001). Using the first language in the classroom. Canadian Modern Language Review, 57, 402-423. https://doi.org/10.3138/cmlr.57.3.402

Creswell, J. W. (2012). Educational research: Planning, conducting, and evaluating quantitative and qualitative research. Boston, MA: Pearson.

De la Campa, J. C., \& Nassaji, H. (2009). The amount, purpose, and reasons for using L1 in L2 classrooms. Foreign Language Annals, 42, 742-759. https://doi.org/10.1111/j.1944-9720.2009.01052.x

Edstrom, A. (2006). L1 use in the L2 classroom: One teacher's self-evaluation. Canadian Modern Language Review, 63, 275-292. https://doi.org/10.1353/cml.2007.0002

Faez, F., \& Valeo, A. (2012). TESOL teacher education: Novice teachers' perceptions of their preparedness and efficacy in the classroom. TESOL Quarterly, 46, 450471. https://doi.org/10.1002/tesq.37 
Friese, S., \& Ringmayr, T. G. (2015). ATLAS.ti (Version 7) [Computer software]. Berlin, Germany: GmbH. Available from http://atlasti.com/

Ghonsooly, B., \& Ghanizadeh, A. (2013). Self-efficacy and self-regulation and their relationship: A study of Iranian EFL teachers. The Language Learning Journal, 41, 68-84. https://doi.org/10.1080/09571736.2013.805017

Gibson, S., \& Dembo, M. H. (1984). Teacher efficacy: A construct validation. Journal of Educational Psychology, 76, 596-582. https://doi.org/10.1037//0022-0663.76.4.569

Glasgow, G. P., \& Paller, D. L. (2016). English language education policy in Japan: At a crossroads. In R. Kirkpatrick (Ed.), English Language Education Policy in Asia (pp. 153-180). New York, NY: Springer.

Kaneko, T. (1992). The role of the first language in foreign language classrooms (Unpublished doctoral dissertation). Temple University, Philadelphia, PA.

Keysar, B., Hayakawa, S. L., \& An, S. G. (2012). The foreign-language effect: Thinking in a foreign tongue reduces decision biases. Psychological Science, 23, 661-668. https://doi.org/10.1177/0956797611432178

Kikuchi, K., \& Browne, C. (2009). English educational policy for high schools in Japan: Ideals vs. reality. RELC Journal, 40, 172-191. https://doi.org/10.1177/0033688209105865

Littlewood, W., \& Yu, B. (2009). First language and target language in the foreign language classroom. Language Teaching, 44, 64-77. https://doi.org/10.1017/s0261444809990310

Liu, D., Ahn, G.-S., Baek, K.-S., \& Han, N.-O. (2004). South Korean high school English teachers' code switching: Questions and challenges in the drive for maximal use of English in teaching. TESOL Quarterly, 38, 605-638.

https://doi.org/10.2307/3588282

Macaro, E. (2005). Codeswitching in the L2 classroom: A communication and learning strategy. In E. Llurda (Ed.), Non-native language teachers: Perceptions, challenges and contributions to the profession (pp. 63-84). New York, NY: Springer.

Mak, S. H-Y. (2011). Tensions between conflicting beliefs of an EFL teacher in teaching practice. RELC Journal, 42, 53-67. https://doi.org/10.1177/0033688210390266

Marlina, R. (2013). [Review of the book Principles and practices for teaching English as an international language, by L. Alsagoff, S. L. McKay, G. Hu, \& W. A. Renandya, Eds.]. World Englishes, 32, 443-445. https://doi.org/10.1111/weng.12043 
McDowell, L. (2009). L1 use in instructions for low-level learners. The Language Teacher, 33(6), 3-7. Retrieved from http://jalt-publications.org/tlt/archive

MEXT. (2010). Heisei 22-nendo kouritsugakkou ni okeru kyouiku katei no hensei jisshi joukyou chousa no kekka ni tsuite [Results on national survey of the implementation of English education in FY2010]. Retrieved from http://www.mext.go.jp/a_ menu/shotou/new-cs/_icsFiles/afieldfile/2011/01/25/1301650_2_1.pdf

MEXT. (2011). Section 9, foreign languages. Retrieved from http://www.mext. go.jp/component/a_menu/education/micro_detail/_icsFiles/afieldfile/2011/04/11/1298356_10.pdf

MEXT. (2014). English education reform plan corresponding to globalization. Retrieved January 2, 2017, from http://www.mext.go.jp/english/topics/_icsFiles/afieldfile/2014/01/23/1343591_1. pdf

Moafian, F., \& Ghanizadeh, A. (2009). The relationship between Iranian EFL teachers' emotional intelligence and their self-efficacy in language institutes. System, 37, 708-718. https://doi.org/10.1016/j.system.2010.05.003

Morris, D. B., \& Usher, E. L. (2011). Developing teaching self-efficacy in research institutions: A study of award-winning professors. Contemporary Educational Psychology, 36, 232-245. https://doi.org/10.1016/j.cedpsych.2010.10.005

Nishino, T. (2012). Modeling teacher beliefs and practices in context: A multimethods approach. The Modern Language Journal, 96, 380-399. https://doi.org/10.1111/j.1540-4781.2012.01364.x

Nishino, T., \& Watanabe, M. (2008). Communication-oriented policies versus classroom realities in Japan. TESOL Quarterly, 42, 133-138. https://doi.org/10.1002/j.1545-7249.2008.tb00214.x

Omote, A. (2012). Ooru ingurishu no jugyou kyoshi wa dou omotte iru no ka?: Intabyuu hou ni yoru kyoshi biriihuno shitsuteki bunseki [What do teachers think of "all-in-English" lesson?: A qualitative analysis on teacher beliefs through interview method]. Journal of Kansai University Graduate School of Foreign Language Education and Research, 10, 21-55.

Polio, C. G., \& Duff, P. A. (1994). Teachers' language use in university foreign language classrooms: A qualitative analysis of English and target language alternation. The Modern Language Journal, 78, 313-326. https://doi.org/10.2307/330110

Richards, J. C., \& Lockhart, C. (1996). Reflective teaching in second language classrooms. New York, NY: Cambridge University Press. 
Tschannen-Moran, M., \& Hoy, A. W. (2001). Teacher efficacy: Capturing an elusive construct. Teaching and Teacher Education, 17, 783-805. https://doi.org/10.1016/s0742-051x(01)00036-1

Turnbull, M. (2001). There is a role for the L1 in second and foreign language teaching, but ... Canadian Modern Language Review, 57, 531-540. https://doi.org/10.3138/cmlr.57.4.531

Turnbull, M., \& Dailey-0'Cain, J. (2009). First language use in second and foreign language learning. Bristol, England: Multilingual Matters.

Weiner, B. (1986). An attributional theory of motivation and emotion. New York, NY: Springer-Verlag.

\section{Appendix A}

\section{Study 1: Questionnaire About Instructional Speech (Original in Japanese)}

This questionnaire investigates your reflection on your instructional speech (in Japanese and English) in the classroom with a view to exploring more effective foreign language teaching and learning. Responses will be statistically calculated for numerical data such as means or percentages. Your complete anonymity will be secured.

\section{Part 1: About Yourself}

1. Sex: male female

2. Mother tongue: Japanese other (

3. Age: $\quad 20-29 \quad 30-39 \quad 40-49 \quad 50-59$ over 60

4. Years of career experience:

$$
\text { 0-5 6-10 11-15 } 16-20 \quad 21-25 \quad \text { over } 26
$$

5. School: 1. elementary 2. lower secondary

3. upper secondary (normal) 4. upper secondary (vocational)

5. vocational college 6. university

6. Grade: 1st 2nd 3rd 4th 5th 6th 


\section{Part 2: About Your Class}

Imagine one main class if you teach more than two classes now.
7. The goal: 1. writing
2. reading
3. listening
4. speaking
5. multi-purpose
6. other (

Hereinafter, please answer the questions about the class you chose in Item 7.
8. Students'
L1: 1 . only Japanese
2. Japanese + other (
3. Japanese + others
4. other language (
9. Class size:
1. less than 10
2. 11-20
3. 21-30
4. $31-40$
5. 41 or more

10. Estimation of students' overall current achievement:
1. $0-20 \%$
2. $21-40 \%$
3. $41-60 \%$
4. $61-80 \%$
5. $81-100 \%$

11. The instruction style is relatively:
1. learner-centered
2. even
3. teacher-centered

12. Main activities relatively focused on:
1. communication
2. even
3 reading comprehension/drills

13. Reflection on the ratio of Japanese (L1) to English (FL) in teacher's speech in tasks (e.g., 4:6 in a total of 10):
L1 : FL =

14. Reflection on the ratio of L1 to FL teacher speech in the classroom management

$$
\text { L1 : FL = }
$$

15. Reflection on the ratio of L1 to FL speech in students' task

L1 : FL =

16. Reflection on the ratio of L1 to FL students' speech in the classroom management

$\mathrm{L} 1: \mathrm{FL}=$

17. Reflection on the ratio of your speech to students' speech in the class

You : Ss = 


\section{Part 3}

Please indicate the extent to which you agree with the items below showing the efficacious function of Japanese/English on the 6-point scale. Please circle the number that most appropriately matches your opinion about the classroom you imagined in the items above. Even if you agree $50 \%$ with the item, please choose either 3 or 4 .

1. I do not agree at all (0\%).

2. I agree a little (up to $20 \%$ ).

3. I do not agree much (up to $40 \%$ ).

4. I agree somewhat (up to $60 \%$ ).

5. I agree mostly (up to $80 \%$ ).

6. I agree very much (up to $100 \%$ ).

A. I feel that Japanese in my class is efficacious because it:

$0 \% \sim 20 \% \sim 40 \% \sim 60 \% \sim 80 \% \sim 100 \%$

18. is effective in goal achievement.

$\begin{array}{llllll}1 & 2 & 3 & 4 & 5 & 6\end{array}$

19. is necessary for goal achievement.

$\begin{array}{llllll}1 & 2 & 3 & 4 & 5 & 6\end{array}$

20. is significant for goal achievement.

$\begin{array}{llllll}1 & 2 & 3 & 4 & 5 & 6\end{array}$

21. is helpful to understand learning contents. $\begin{array}{lllllll}1 & 2 & 3 & 4 & 5 & 6\end{array}$

22. is helpful to enhance understanding. $\quad \begin{array}{llllllll}1 & 2 & 3 & 4 & 5 & 6\end{array}$

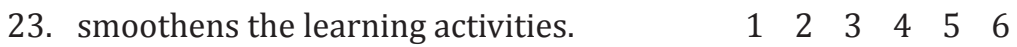

24. enriches learning during learning activities. $1 \begin{array}{llllll}1 & 2 & 3 & 4 & 5 & 6\end{array}$

B. I feel that English in my class is efficacious because it:

25. is effective in goal achievement.

$\begin{array}{llllll}1 & 2 & 3 & 4 & 5 & 6\end{array}$

26. is necessary for goal achievement.

$\begin{array}{llllll}1 & 2 & 3 & 4 & 5 & 6\end{array}$

27. is significant for goal achievement.

$\begin{array}{llllll}1 & 2 & 3 & 4 & 5 & 6\end{array}$

28. is helpful to understand learning contents. $\begin{array}{lllllll}1 & 2 & 3 & 4 & 5 & 6\end{array}$

29. is helpful to enhance understanding. $\quad \begin{array}{lllllll}1 & 2 & 3 & 4 & 5 & 6\end{array}$

30. smoothens the learning activities. $\quad \begin{array}{lllllll}1 & 2 & 3 & 4 & 5 & 6\end{array}$

31. enriches learning during learning activities. $1 \begin{array}{llllll}1 & 2 & 3 & 4 & 5 & 6\end{array}$ 


\section{Appendix B}

\section{Study 2: Interview Protocol}

Questions asked

1. What learning experiences did you have prior to becoming a teacher? Explain.

- Do you recall something motivational about your own mastery of English?

- Do you recall a teacher who had a great influence on your efficacy?

2. What mastery experiences have made you efficacious?

- How do you know that a given lesson has or has not gone well in terms of speech? Explain.

3. Can you pinpoint some powerful vicarious influences on your teaching efficacy?

- Can you recall things you have observed that made you efficacious as a teacher? Explain.

4. Can you recall something students or other teachers have said or shown about your teaching?

- Did the comment they made to you increase or decrease your efficacy? Explain.

5. Identify some of the most prominent feelings and emotions that you experience while teaching.

- Which feelings or emotions have most profoundly influenced your efficacy? Explain.

6. Tell me advantages and disadvantages that teachers face in relation to the English-only policy.

Note. Modified from Morris and Usher (2011). 